\title{
Reframing the Dominant Diversity Discourse: Alternate Conversations for Creating Whole System Change
}

\author{
Frank D. Golom
}

\begin{abstract}
Diversity and inclusion (D\&I) efforts in higher education are decades old, yet progress continues to be slow and elusive for many campuses. Recent events in colleges and universities across the United States suggest that long-standing challenges related to access, equity and inclusion remain as entrenched and intractable as they have ever been, resulting in campus environments that may be unwelcoming or hostile to faculty, staff and students from underrepresented groups. One reason for the partial success of university D\&I programs is that they overemphasize individual actors, attitudes and behaviors while neglecting the systemic, organizational cultures in which those actors reside. Drawing on the organization development and change literatures, this paper offers three alternate perspectives for reframing campus diversity work, arguing that all D\&I initiatives must consider the (a) contextual, (b) multilevel and (c) systemic nature of change if they are to be robust and successful.
\end{abstract}

Keywords: inclusion; systems thinking; organization change; organization development; multicultural affairs

\section{Introduction}

Institutions of higher education have been attending to issues of diversity and inclusion (D\&I) for decades (Harvey, 2016). Such attention can be seen in a number of important and consequential D\&I initiatives, including efforts to increase the recruitment and retention of students and faculty from underrepresented backgrounds, the development of specific affinity programming, spaces and offices for minority students, the creation of targeted administrative positions to lead and manage diversity efforts, and training and other psychoeducational programs aimed at educating the broader campus, and the general public, on a number of important topics critical to increasing multicultural competence in the $21^{\text {st }}$ century (e.g., prejudice, discrimination, identity, microaggressions, social justice).

These efforts are long-standing, necessary, responsive and consistent with the aim of expanding access to higher education in the United States. And these efforts are often unsuccessful (Dobbin \& Kalev, 2016; Eagly, 2016). Despite decades of attempts at increasing access, equity and inclusion for underrepresented groups, and despite some progress with respect to the diversification of students and faculty, there remains considerable work to be done, and considerable dissatisfaction with campus climates that are deemed unwelcoming or hostile. The current article offers an organizational systems perspective (Senge, 1990) on the state of D\&I efforts in higher education, and argues that many of our efforts at diversity and inclusion fail because they do not make the whole system the target of the change effort (Block \& Noumair, 2017). It also offers several ways of conceptualizing and framing campus D\&I efforts from an 
organization-wide, total system, culture change perspective in the hopes of increasing the depth, longevity and success of their impact. To that end, the article is grounded in the change and diversity literature in organizational psychology and organization development (e.g., Burke, 2017), and not necessarily in more traditional writing in higher education or social justice.

\section{Recent Conversations in the Diversity and Inclusion Space}

Over the last several years, there has been increased attention to issues of diversity, inclusion and multicultural competence in higher education, fueled in part by the larger national climate and public outrage over racial injustice in the United States, including the deaths of a several unarmed African American men at the hands of police officers in Missouri, New York and Maryland. Campus walkouts, protests, sit-ins and uprisings, often in solidary with residents in Ferguson, Staten Island and Baltimore, have become common, receiving coverage in The Chronicle of Higher Education, The Associated Press, The New York Times, The LA Times and The Washington Post. The Atlantic even compiled an interactive "cheat sheet and timeline" from some of the more well-known campus protests, including those at Harvard, Yale, Claremont McKenna and the University of Missouri (Wong \& Green, 2016).

These demonstrations and the actions they spurred were attempts at producing real change by and on behalf of students who have been historically marginalized. Student groups from at least 80 colleges and universities have requested a variety of actions from campus administration. These actions, collected and listed in full by the website TheDemands.org, are attempts at initiating, re-invigorating and maintaining some of the efforts that have typified the higher education multicultural equity landscape for decades, including increased recruitment of students and faculty of color and training for all faculty, administrators and staff on issues of racial justice and microaggressions, the "brief and commonplace daily verbal, behavioral, and environmental indignities, whether intentional or unintentional, that communicate hostile, derogatory or negative slights and insults to the target person or group” (Sue et al., 2007, p. 273).

Yet even with the increased attention surrounding these movements, the demands put forth by the students and the actions taken by some administrators, actual change with respect to campus diversity and inclusion has been harder to achieve. According to a recent report in The New York Times, "black and Hispanic students are more underrepresented at the nation's top colleges and universities than they were 35 years ago" (Ashkenas, Park, \& Pearce 2017). Despite decades of attempts to recruit individuals from marginalized backgrounds, the percentage of African American first-year students at top US institutions remained "virtually unchanged since 1980," and the proportion of Hispanic first-year students at these institutions did not keep pace with US population trends over the same period.

A plausible take-away from these data, and the last few years of headline-grabbing campus activism, is that institutions of higher education, much like their corporate counterparts, have not produced as much D\&I change as they had hoped (Dobbin \& Kalev, 2016; Eagly, 2016). Although there are many reasons for the lack of progress, one explanation lies in the way some diversity and inclusion advocates have been framing and approaching their work, frequently choosing to focus their conversations and actions on specific individual instances of oppression rather than on the systemic organizational forces that keep such cycles of oppression locked in 
place (Davidson, 1999). William B. Harvey, the former a vice president and director of the Center for Advancement of Racial and Ethnic Equity at the American Council on Education and a distinguished scholar at the American Association for Access, Equity, and Diversity, framed the question this way in an important article published (Harvey, 2016) in the Chronicle: "How many protests will it take to finally diversify our campuses?”

Harvey recounts a telling anecdote that encapsulates just how little systemic, structural change has been produced in higher education when it comes to diversity and inclusion. He includes the following passage from another essay he penned, which he started distributing to bewildered colleagues during the campus protests of late 2015 and early 2016:

While greater numbers of minority-group students are matriculating at colleges and universities than ever before, to a large degree those students find themselves outside the mainstream of campus life. At best, the feeling that many have is that their presence is simply tolerated as a politically expedient maneuver; at worst, they feel they are the victims of subtle - and sometimes not so subtle - racist attitudes and practices on the part of classmates and instructors alike.

As Harvey notes, although colleagues frequently agreed with the sentiments expressed, they were somewhat incredulous and confused when he recounted that the article he was quoting from had originally been published 36 years ago in 1981. The new, novel and surprising campus uprisings of the last few years were, according to Harvey, just "a chronic case of racial déjà vu." From an organization change perspective, they were also a good illustration of just how limited individually-focused and isolated programming can be when it comes to transforming the culture of an entire organizational system, and therefore, producing and maintaining sustainable change.

\section{Shifting the Conversation: An Organization Change Perspective}

While the claim of racial déjà vu is more anecdotal than empirical, it is consistent with decades of writing in the organizational psychology and development literatures on when organizational systems produce change, and when they do not. By some estimates, two-thirds of organization change efforts fail, unable to meet their desired objectives (Burke, 2017) and often producing a considerable amount of resistance in the process. The reasons for these failure rates are many, and include technical challenges like unclear visions, active political opposition, ineffective leadership, poor implementation and inadequate communication (Burke, 2017; Pasmore, 2011). Yet, beyond the technical, behavioral and administrative drivers of organization-change failure, one additional reason for the lack of success of many change initiatives is that change leaders often do not make the entire organizational system the target of the change effort (Burke, 2017; Senge, 1990), focusing instead on specific individual events rather than on the deeply engrained patterns, norms, cultures - or the larger systemic context - that allow such events to occur.

To understand this aspect of failure more fully, it is helpful to review basic tenets of systems theory as they apply to an organizational context. Senge (1990) defines a system as "anything that takes its integrity, form and definition from the ongoing interaction of its elements... all of which have a common purpose and behave in common ways" (Senge, 1990, p. 137). More simply, a system can be best thought of as a set of elements "interconnected in such a way that 
they produce their own pattern of behavior over time” (Meadows, 2008, p. 2). Different systems theorists distill the elements of organizational systems in various ways (e.g., Burke \& Litwin, 1992; Meadows, 2008; Svyantek \& Brown, 2000), but a useful classification is provided by Senge (1990), who distinguishes between the structural, functional and behavioral elements of any system. The structural element, which refers to "the basic interrelationships that control behavior and translate perceptions, goals, rules and norms into action” in any organization, includes hierarchies, information-flows and general decision-making processes (Senge, 1990, p. 40). The functional element describes the long-term patterns of behavior between actors that often result from the organization's structural makeup, similar to the organization's personality, or response tendencies. And, the behavioral element refers to an organization's specific, individual responses to a given situation, including specific events embedded in its overall pattern of behavior, or more plainly stated, its “who-did-what-to-whoms” (Golom, 2015).

In many change initiatives and in most organizations, the pull is to conceptualize change by focusing on these individual behavioral elements in isolation, rather than thinking about the patterns and structures that lock seemingly disconnected elements together or cause them (Burke, 2017; Senge, 1990). For example, in the diversity and inclusion space, organizations frequently require training in response to biased or insensitive behavior among organizational members (Davidson, 1999). Yet, when attention in day-to-day organizational life is placed on individuallevel events instead of considering what those events reveal about the organization's culture, the result is often a series of interventions aimed at improving unbearable symptoms, without ever attending to their underlying cause. Organizations committed to addressing change in this way appear actively and reactively busy, calming isolated and even repeated crises, but their cumulative work may not produce substantive change. In fact, a structural approach to change is perhaps the only way to have a significant impact on an institution's culture, correcting deeply and often unconsciously embedded ways of responding and altering the context so that certain events are less likely to occur (Burke, 2017; Senge, 1990; Golom, 2015).

The failure to target organizational culture is the death knell of many change initiatives (Katzenbach, Steffen \& Kronley, 2012). This is particularly true in the diversity and inclusion space, which is, in the literature and in practice, rarely framed from an organization change or whole systems perspective (Block \& Noumair, 2017; Foldy \& Buckley, 2017). Block and Noumair (2017) articulated this challenge in a recent special journal issue devoted to thinking about diversity and inclusion systemically, noting that current D\&I practice and scholarship mostly emphasize "individual-level understanding and interventions, via providing extra knowledge and skills training for women and people of color, or providing bias awareness training for leaders and managers” (p. 150). Research suggests, however, that such individuallevel interventions are often unsuccessful in producing large-scale diversity change in organizations (Dobbin \& Kalev, 2016), particularly with respect to the representation of women and people of color in top management positions and employee perceptions of the institutional climate. As Block and Noumair (2017) note, such failure occurs in part because D\&I practitioners frequently ignore "the role that systemic factors play in influencing diversity and inclusion in organizations," thereby ensuring that "diversity initiatives are enacted narrowly, making change in part of the system rather than in the whole system," if at all (p. 150). 
Such omissions are as true in higher education as they are in the corporate world, as colleges and universities frequently focus their D\&I conversations at the individual-level, spurred in part by specific campus or national "crisis" events that demand immediate attention and reaction from students. Not only is this the dominant frame on change in many organizations, it is a model that has been employed in higher education since multicultural affairs offices began populating student development in the 1970s and 1980s (Patton \& Hannon, 2008). These offices are engaged in the important work of attending to the experiences, academic success and psychological well-being of underrepresented students who exist in campus environments that may be both subtly and overtly hostile to them, but as a general rule, they are rarely responsible for or have authority over direct system-wide culture change on behalf of their constituents. Thus, the cycles of justice and equity activity that grip higher education every few years are more about attending to individuals than changing the organizational culture, which is, both conceptually and in practice, a significant driver of the lack of progress frequently cited (Harvey, 2016) by underrepresented individuals on university campuses. In order to produce total system change, D\&I practitioners have to shift the conversation and consider framing and enacting their work from an organizational, or total system, change perspective.

\section{Alternate Diversity Dialogues: Context, Levels and Systems}

Framing diversity and inclusion work as an organization change initiative requires holding at bay reactions to specific, individual events and instead examining patterns, interrelationships and feedback mechanisms across the organizational system. It also requires engaging in conversations that do not always dominate the daily work of diversifying higher education institutions, which as the evidence reviewed earlier indicates, has been overtaken by reactions to local and national crises, uprisings and student demands, many of which include individual-level interventions (e.g., screening for bias, diversity training, grievance policies) that are not strongly supported in the research (Dobbin \& Kalev, 2016; Eagly, 2016). These conversations are based on the theoretical and empirical literature in the field of organization development, and emphasize attending to organizational context, higher levels of analysis and systems dynamics in addition to the immediate individual event or concern of the moment, regardless of how important, pressing or unacceptable that individual element might be.

\section{Conversation \#1: The Context Conversation}

Social and organizational psychologists have for decades reinforced the idea that we frequently make individual attributions regarding the causes of other people's behavior, while at the same time offering contextual rationales for our own. For example, we are more likely to discuss others' bad actions as being a fundamental reflection of who they are, while excusing our own with a litany of outside forces that affected us and of which those around us would be unaware (Ross, 1977). This fundamental attribution error often results in individuals forgetting the simple idea that behavior in organizations is jointly determined by two factors: those related to the individual person as well as those related to the larger group and organizational context in which that person resides (Chatman, 1989; Lewin, 1951). This interactionist perspective is essential for navigating the complex, diverse environments of most modern organizations, as it forces the recognition that the organizational context can be as strong an influence on organizational behavior as personality variables (Chatman, 1989). 
In higher education D\&I work, a considerable amount of attention is placed on individual elements, including individual instances of intolerance on campus, individual student complaints and individual faculty members and administrators who do not 'get it' with respect to diversity and social justice issues. The attention to the individual-level is necessary, but empirical research suggests it is insufficient for conceptualizing and addressing diversity and inclusion challenges in an organizational setting. In effect, context matters, as context can induce behavior in strong organizational environments that overrides one's personality dispositions (Chatman, 1989). In higher education, what counts as context is far-ranging, including institutional classification (e.g., Carnegie classification), history, mission, cultural norms, legislative environment, demographic composition, curriculum, organizational systems and community partnerships. For example, many campuses have specific policies and procedures for reporting and addressing bias against underrepresented students. In a recent meeting at one university, students began to criticize the bias reporting system for a lack of follow-through on submitted complaints. The administrator charged with overseeing bias reporting insisted that she gave every complaint reported her due diligence and care, and a lengthy conversation ensued about whether the bias reporting system was functioning as intended.

To keep the conversation at the level of the reporting system and its functioning, however, misses a larger contextual data point about the culture of the institution and how it might be contributing to the occurrence of biased events in the first place. An interactionist perspective moves beyond individual incidents of bias or microaggression to consider the context of those incidents, and to wonder what group and organizational-level variables are preventing individuals who would suppress such biases in other contexts from doing so in their current setting. Microaggressions, for example, do not occur in a vacuum (Lilienfeld, 2017). They occur in a context that, depending on its contents, may make their expression more or less likely. Ensuring that the organizational environment is not fertile ground for such incidents is a far better and more effective strategy than only addressing each individual microaggressive event as, or more likely after, it occurs. Metaphorically-speaking, the latter approach is the equivalent of preventing weeds in a garden by pulling each one out as it appears, rather than simply treating the soil to make weed growth less likely, and then periodically attending to an occasional outlier.

\section{Conversation \#2: The Levels Conversation}

One of the unintended consequences of overly focusing the D\&I conversation on individual events, elements and actors is that our change initiatives become focused at the individual-level as well. In short, an individual frame begets common individual interventions, including recruiting, retaining, replacing, displacing, training and coaching particular individuals or a set of individuals (Burke, 2017). Unfortunately, there remains little evidence in the organizational literature that changing individuals results in a changed organizational system (Burke, 2017). First, D\&I interventions are frequently reactive in nature and often occur absent a larger organizational D\&I strategy (cf. Thomas, 2004), "not in the service of moving the total system in a new direction" (Burke, 2017, p. 101). Second, sometimes change occurs in the opposite direction of what was intended, as some common individual-level diversity interventions have been shown to create backlash or decrease the representation of underrepresented groups in leadership roles (Dobbin \& Kalev, 2016). 
The organizational literature on the effectiveness of diversity training offers an illustration regarding the limitations of individual-level change interventions, especially when one considers that a frequent student demand during the 2015-2016 campus protests was some form of diversity training. Of the 80 schools featured on TheDemands.org, most of their student groups demanded some form of diversity, racial justice or microaggressions training. Yet, according to a number of empirical studies, such training is more likely than not to be incomplete, ineffective or produce resistance (Bezrukova, Jehn \& Spell, 2012). For example, in their review of common diversity practices in 708 private sector organizations, Kalev, Dobbin and Kelly (2006) discovered that "practices that target managerial bias through feedback (diversity evaluations) and education (diversity training) show virtually no effect in the aggregate. They show modest positive effects when responsibility structures are also in place. However, they sometimes show negative effects otherwise. Research to date from HR experts and psychologists suggests that interactive training workshops, of the kind we examine, often generate backlash (p. 611).

In some ways, the lack of findings here and in other studies of a similar nature are not surprising. Exclusively targeting the individual level ignores the multiple levels that exist in and around any organization, including higher-order group, department, university, industry and national forces that influence students, faculty and staff long after the training has ended. At the very least, D\&I interventions that address specific units or departments within the university (i.e., group training or group coaching) may yield more dividends than programs that attempt to educate individuals from various quarters of the campus, in part because they may promote the establishment of group norms and knowledge structures that can remain in place after the training has ended (Kulik, Roberson \& Tan, 2013; Liang, Moreland \& Argote, 1995).

\section{Conversation \#3: The Systems Conversation}

To consider context and levels more explicitly in the pursuit of diversity and inclusion work is to begin to adopt a systems perspective on creating change. As an oversimplification, one of the challenges of our dominant discourse on diversity and inclusion in higher education is that it does not always involve a systems conversation. In fact, if both diagnosis and intervention remain at the individual level, a systems conversation cannot by definition occur and a lack of progress is almost guaranteed. To think in systems is to attend to context and level of analysis, as has been said, but also to the structural interdependence, interrelatedness and patterns between and among different aspects of the system, both in any given moment and over time. In organizational systems, these structures and patterns are best understood as organizational culture, or the "beliefs, values and behavioral norms that come to be taken for granted as basic assumptions and drop out of awareness," even as they are implicitly "taught to new members as the correct way to perceive, think, feel and behave in relation to problems” (Schein, 2016, p. 6).

Culture is paramount because it outlasts any one individual event or element within the organizational system, in part because it is structurally stable, deeply unconscious, pervasively broad and subtly integrating of disparate events and activities (Schein, 2016). For example, one of the issues facing higher education D\&I leaders right now is the inclusion and protection of transgender students and faculty. Institutions have taken up the causes of transgender individuals on campus, including the important issue of providing all gender restrooms and housing options. 
This attention to transgender issues is needed, important and critical to the safety, learning and well-being of trans students, and it also parallels the attention previously paid to the safety, learning and well-being of gay, lesbian and to a lesser extent bisexual students in the 1990s (Renn, 2009). It is likely that other queer-identified students will receive attention in the coming decade, in a cyclical yet often unacknowledged pattern of welcoming in a new sexual minority "other" that had previously gone ignored. On the one hand, this is the nature of diversity and inclusion work, expanding the circle to an ever-widening array of marginalized individuals. On the other hand, it suggests that previous attempts at change may have focused heavily on one individual group of students or one social identity, rather than thinking about the ways in which the organizational culture and system, particularly its heteronormative or gendered basic assumptions, could be changed so as to allow a more seamless integration of students, faculty and staff of diverse sexual expression.

A focus on changing the deeply embedded cultural norms of a whole organizational system is decidedly a different conversation, but if the goal is to enhance equity and inclusion for all types of underrepresented groups in the academy, it is a required one. Fundamentally altered organizational behavior requires an altered system (Golom, 2015), and while many have adopted the language of "systemic issues" or "systems," it is much harder to make the paradigm shift required to think systemically or implement that thinking practically in an organizational context (Meadows, 2008). In part, the challenge with implementation rests in the fact that systems are not static; they are dynamic entities that seek to maintain equilibrium at all costs and that frequently fall into entrenched patterns of responding (Meadows, 2008; Coleman et al., 2017). As a result, not only are they difficult to see or change, they also difficult to maneuver, and will frequently return to homeostasis, particularly in the face of narrow or isolated attempts to alter them (Meadows, 2008). The only way to change an organizational system is to change its culture, to shift its norms, values, beliefs and attitudes out from underneath it to an altered, more diverse and inclusive state, often without it realizing what those norms are and without engendering too much resistance.

\section{Translating the Conversations: Systems Blueprints for Change}

Thinking systemically is a tall order for any change initiative; for deeply personal and identityrooted D\&I work, it requires the utmost skill, patience and tolerance for ambiguity. A frequent critique of systems approaches to change is that they are interesting diagnostically, but do not easily lend themselves to intervention, implementation and action (Meadows, 2008). Although this critique is valid, the alternate conversations suggested in this article are examples of how D\&I practitioners can begin to adopt more of an organization change frame in their work, and how they can shift their conceptual models and mindsets toward greater systems acumen. Examples of how common D\&I challenges and interventions might be reframed and approached from a context, levels or systems perspective are provided in Table 1. 
Table 1: Common D\&I Challenges and Interventions Reconsidered from a Context, Levels and Systems Perspective

\begin{tabular}{|c|c|c|c|c|}
\hline Challenge & $\begin{array}{l}\text { Individual-Level } \\
\text { Intervention }\end{array}$ & $\begin{array}{c}\text { Context } \\
\text { Considerations }\end{array}$ & $\begin{array}{c}\text { Levels } \\
\text { Considerations }\end{array}$ & $\begin{array}{c}\text { Systems } \\
\text { Considerations }\end{array}$ \\
\hline $\begin{array}{l}\text { Several faculty are } \\
\text { concerned about the } \\
\text { lack of queer } \\
\text { individuals on the } \\
\text { faculty and in } \\
\text { senior administrator } \\
\text { roles. }\end{array}$ & $\begin{array}{l}\text { In the next round } \\
\text { of faculty hiring, } \\
\text { the provost's } \\
\text { office devotes } \\
\text { additional } \\
\text { resources to } \\
\text { identifying and } \\
\text { recruiting queer } \\
\text { faculty. }\end{array}$ & $\begin{array}{l}\text { Is the climate on } \\
\text { campus favorable } \\
\text { for queer- } \\
\text { identified } \\
\text { individuals, and } \\
\text { how is scholarship } \\
\text { on queer issues } \\
\text { viewed? }\end{array}$ & $\begin{array}{l}\text { How would the } \\
\text { inclusion of } \\
\text { queer faculty in } \\
\text { certain } \\
\text { departments } \\
\text { impact group } \\
\text { cohesion, } \\
\text { communication, } \\
\text { conflict and } \\
\text { trust? }\end{array}$ & $\begin{array}{l}\text { How might } \\
\text { institutional } \\
\text { heterosexism be } \\
\text { manifest in } \\
\text { formal and } \\
\text { informal } \\
\text { campus policies, } \\
\text { procedures and } \\
\text { systems? }\end{array}$ \\
\hline $\begin{array}{l}\text { A coalition of } \\
\text { underrepresented } \\
\text { students, } \\
\text { unsatisfied with } \\
\text { what they perceive } \\
\text { as a negative } \\
\text { climate on campus, } \\
\text { hold a series of } \\
\text { demonstrations to } \\
\text { voice their } \\
\text { experiences of } \\
\text { microaggressions. }\end{array}$ & $\begin{array}{l}\text { University } \\
\text { administrators, in } \\
\text { response to } \\
\text { student } \\
\text { demonstrations, } \\
\text { implement } \\
\text { mandatory } \\
\text { diversity training } \\
\text { for faculty, staff } \\
\text { and students. }\end{array}$ & $\begin{array}{l}\text { Does the } \\
\text { university } \\
\text { curriculum and } \\
\text { programming } \\
\text { include multiple } \\
\text { psychoeducational } \\
\text { opportunities for } \\
\text { learning about } \\
\text { issues of social } \\
\text { justice, diversity } \\
\text { and inclusion? }\end{array}$ & $\begin{array}{l}\text { How does } \\
\text { training support } \\
\text { an overall } \\
\text { vision, strategy } \\
\text { and action plan } \\
\text { for campus } \\
\text { diversity efforts } \\
\text { at the } \\
\text { university- } \\
\text { level? }\end{array}$ & $\begin{array}{l}\text { What are the } \\
\text { potential points } \\
\text { of resistance to } \\
\text { mandatory } \\
\text { training, and } \\
\text { how and where } \\
\text { on campus are } \\
\text { they likely to } \\
\text { manifest? }\end{array}$ \\
\hline $\begin{array}{l}\text { A student of color } \\
\text { has complained } \\
\text { about a faculty } \\
\text { member's biased } \\
\text { behavior, including } \\
\text { racially insensitive } \\
\text { and politically- } \\
\text { charged comments. }\end{array}$ & $\begin{array}{l}\text { The student is } \\
\text { encouraged to } \\
\text { file a formal bias } \\
\text { complaint or } \\
\text { grievance, which } \\
\text { is then } \\
\text { investigated by } \\
\text { the appropriate } \\
\text { university } \\
\text { official. }\end{array}$ & $\begin{array}{l}\text { How is this } \\
\text { dynamic } \\
\text { reflective of or } \\
\text { influenced by } \\
\text { current (or } \\
\text { historical) } \\
\text { university, } \\
\text { regional or } \\
\text { national patterns } \\
\text { and trends? }\end{array}$ & $\begin{array}{l}\text { Are the faculty } \\
\text { member's } \\
\text { actions an } \\
\text { isolated event, } \\
\text { or do they imply } \\
\text { something about } \\
\text { the climate for } \\
\text { diversity in his } \\
\text { or her } \\
\text { department? }\end{array}$ & $\begin{array}{l}\text { What implicit } \\
\text { norms are } \\
\text { present on } \\
\text { campus that } \\
\text { tacitly condone } \\
\text { or allow faculty } \\
\text { to remain } \\
\text { ignorant of } \\
\text { issues of racial } \\
\text { justice? }\end{array}$ \\
\hline
\end{tabular}


Additionally, a number of systems models exist in the organization change and development (Burke, 2017) and higher education (Dowd \& Bensimon, 2015) literatures that can offer guidance to faculty, administrators and students as they consider strategic planning around campus diversity and equity initiatives. These models distill the context, levels and systems conversations reviewed here into practical blueprints for change that include the main factors, leverage points and interrelationships that exist at the core of any organizational system. For example, using an open systems model of organizational performance and change (Burke \& Litwin, 1992), Golom (2015) proposed seven recommendations for applying a systems lens to campus diversity work around queer student issues, and provided an in-depth case study of one university's attempt to put the recommendations into practice. Summarized in Table 2, these recommendations include (1) manipulating the context to create a strong sense of urgency, (2) developing a vision for change that sticks, (3) involving the "right" people to communicate the vision, (4) aligning day-to-day organizational behavior with the new vision, (5) sustaining and institutionalizing the vision, (6) rewarding and celebrating small successes, and (7) evaluating and recalibrating the change goals.

Table 2: Recommendations for Effecting Institutional Change around Diversity Issues (Golom, 2015)

Recommendation 1: $\quad$ Manipulate the context by creating a strong sense of urgency

Recommendation 2: Harness and channel momentum by developing a compelling vision for the change effort that sticks

Recommendation 3: $\quad$ Involve the right people to communicate and reinforce the vision

Recommendation 4: Align day-to-day organizational life with the new vision (and stop behavior that interferes with that alignment)

Recommendation 5: $\quad$ Independently sustain and institutionalize the vision

Recommendation 6: $\quad$ Orchestrate, reward and celebrate small successes

Recommendation 7: $\quad$ Evaluate, titrate and recalibrate the change effort

A full discussion of all seven recommendations can be found elsewhere (Golom, 2015), but two merit review here, both because of their importance in creating and sustaining change and because they often need to be customized to fit the mission and culture of a particular institution in order to be successful. First, the initial step of any change initiative is to create a sense of urgency. According to the literature, urgency serves to build the necessary momentum and readiness for change to occur, and is often achieved by surfacing dissatisfaction with the status quo (Burke, 2017). How that dissatisfaction is surfaced, however, can take on different meanings for different constituent groups and different campuses. The task for D\&I practitioners is to 
define urgency for their institution in a way that is likely to resonate with the mission of the organization and its members. For example, at a recent workshop where the above recommendations were presented, one participant commented that he had been showing demographic data to faculty and administrators for years to no avail. He consistently highlighted the dearth of minority faculty and staff compared to changing student demographics, yet he saw no increased motivation to change beyond those already motivated.

Based on experience, this is not an uncommon phenomenon or complaint, and one that occasionally devolves into a discussion of all that is 'wrong' with the people who just "do not get" the data. It may be more useful, though, to consider the meaning of that data in context. Although data are particularly helpful with respect to capturing and evaluating the progress of any change work, they are not uniformly instrumental in persuading individuals to action, particularly those who do not use data regularly or who may have trouble seeing the story behind the information (Dowd, Bensimon \& Witham, 2016). To use data unartfully with these individuals is a risk from an urgency perspective, and may require either technical assistance or a reframe on the use of data from a psychological perspective. D\&I practitioners, who are able to see the story in their institutional data, would benefit from thinking about the cognitive and emotional reactions those data generate, and then considering alternate methods for bringing about the same reactions in those who are not data friendly (e.g., student narratives, intergroup dialogues). Alternatively, The Center for Urban Education uses an interactive program called the Benchmarking Equity and Student Success Tool (BESST) that is designed to help faculty and administrators illuminate the 'story' behind the data for those unaccustomed to working with such information (Dowd, Bensimon \& Witham, 2016). Regardless of the approach used, from an urgency perspective, it is important to note that not all data are equal nor are they equally compelling. In most cases, the data alone are not creating a sense of urgency. What creates urgency is how the data make individuals feel.

Second, although urgency is in effect the sine qua non of any change initiative, urgency by itself is insufficient and generally unsustainable, as it often relies on crises cycling through the system at predictable intervals to rebuild momentum. If one wishes to guide D\&I work beyond a reactive and event-based approach, urgency must be translated into a compelling and strategic vision for moving forward that is reinforced at all levels of the organization. From an equity perspective, clear goals and objectives are essential (Dowd, Bensimon \& Witham, 2016). A wellarticulated and thoughtful vision offers organizational members an end state toward which they can guide their various initiatives. Furthermore, research is clear about the powerful effects of goal-setting on motivation and performance (Locke \& Latham, 2002). A compelling vision offers a superordinate goal that can help keep diverse constituencies aligned and unified over the course of a change effort, which is at times bound to be nonlinear, chaotic and full of ostensibly competing agendas (Burke, 2017).

Several recent examples illustrate the power of a strategic vision and the detrimental effects of its absence. For instance, religiously-affiliated institutions often struggle with the inclusion of lesbian, gay, bisexual, transgender (LGBT) and other queer-identified students, faculty and staff. One potential way through these struggles is to explicitly link queer change efforts to the religious mission of the institution, often by citing religiously-based values associated with community, justice and service to the disadvantaged or the underserved (Golom, 2015). 
Although certain segments of the campus may bristle at such a deliberate connection, scholars suggest that embedding diversity work into an institution's pre-existing mission, culture or strategy ensures that it is much more likely to be successful (Thomas, 2004).

Along these lines, it may be helpful to consider examples from the student demands mentioned earlier, which originated from campus uprisings against racial injustice. In the spring of 2015, students of color at one university gathered in solidarity with antiracist demonstrations across the nation. Part of the gathering involved sharing painful experiences of racial microaggressions on a large banner. The statements written on the banner were disturbing and gut-wrenching, and were made available far and wide across the campus. On the one hand, these statements certainly created a sense of urgency among university faculty and administrators, including individuals for whom D\&I concerns were not typically top of mind. On the other hand, that sense of urgency occurred without a larger, campus-wide conversation about a strategic plan or vision for diversity, broadly defined, moving forward. Instead, the students demanded, and the administration consented, to a number of individual-level programmatic initiatives that have repeatedly been shown to have mixed empirical support in the literature, including mandatory diversity training focused on a narrow definition of diversity (Kulik, Roberson \& Tan, 2013). More than two years later, that training has only been piloted in portions of the campus, and the sense of urgency that many thought would bring about real change appears to have lessened, especially as many of those originally involved have graduated or exited the institution.

In some ways, this outcome is not surprising. As Dowd, Bensimon and Witham note (2016), “instead of thinking about equity as a 'targeted strategy' that can be achieved through one particular office or program, institutions should approach equity as a normative standard for all aspects of the institution, from resource allocation to assessment to strategic planning." In other words, successful equity work requires whole system change, and that requires shifting the overall culture of higher education by: (a) attending to the larger context of the change effort (e.g., sense of urgency); (b) linking individual-level behavior and higher-level organizational factors (e.g., day-to-day organizational behavior with clear change visions, objectives and goals); and (c) considering how programs and interventions can be strategically aligned to shift the organization's implicit norms and assumptions about the kinds of people and issues to which it has traditionally attended.

Unfortunately, this is a process that, by its nature, can only occur slowly and over time. Culture change may be the ultimate goal of any systemic change effort, but practitioners are often unsuccessful changing culture by directly trying to change it (Burke, 2017; Lorsch \& McTague, 2016). Instead, culture change is often achieved by envisioning the behaviors needed to bring about new cultural norms and values, and then slowly reinforcing those behaviors through altered performance evaluations, incentive structures and decisional authority (Lorsch \& McTague, 2016) until equity and inclusion become "pervasive” features of organizational life (Dowd, Bensimon \& Witham, 2016).

\section{A Systems Caveat}

The examples, blueprints and recommendations mentioned above and summarized in Tables 1 and 2 are important illustrations of what a systems lens on D\&I work entails, and their inclusion 
at the end of this article is meant to provide specific and helpful illustrations for some of the principles covered. Yet, if one is truly thinking systemically, a list of specific actions that can be taken to produce change misses the very essence of the nature of organizational systems; it is inherently better to help individuals understand the general rules and principles that underlie a system's behavior than to produce a list of acontextual, ahistorical and frozen-in-time actions that should always be taken or always demand attention. Helping organizations and individuals shift their paradigms, mindsets and models toward thinking systemically is a better leverage point for creating change than any one specific intervention (Meadows, 2008). A list of reactive, event-driven and strategically void initiatives can never additively produce total system change.

\section{Conclusion}

The purpose of this article was to offer an organizational systems perspective on the state of D\&I efforts in higher education. I argue that many of our efforts at diversity and inclusion fail because they do not make whole system change the target of those efforts. I further suggest that those interested in making academia more inclusive for a variety of underrepresented groups consider how attending to the context, levels and systems surrounding individual events and behavior can enhance their work. To that end, the alternate conversations included in the article are meant to complement our existing approaches to increasing access, equity and inclusion in higher education, to emphasize that those approaches are often static while systems are not, and to expand the conversation we have been recently having in a more dynamic and productive way. Adopting these conversations is not a magic bullet for the success of any diversity and inclusion initiative, nor is it easy. However, to continue to stay at the level of individual interventions is to be complicit with the organizational system in maintaining the status quo, resisting change and allowing the culture of the university to remain unscathed. That may appease different individuals and social groups at different points in time, but it will never offer many of us in higher education the diverse and inclusive future we seek. 


\section{References}

Ashkenas, J. Park, H. \& Pearce, A. (2017, August). Even with affirmative action, blacks and Hispanics are more underrepresented at top colleges than 35 years ago. New York Times. Retrieved from http://www.nytimes.com

Bezrukova, K., Jehn, K. A. \& Spell, C. S. (2012). Reviewing diversity training: Where we have been and where we should go. Academy of Management Learning and Education, 11(2), 207222. https://doi.org/10.5465/amle.2008.0090

Block, C. J. \& Noumair, D. A. (2017). Understanding diversity dynamics in systems: Social equality as an organization change issue. Journal of Applied Behavior Science, 53(2), 150-155. https://doi.org/10.1177/0021886317703250

Burke, W. W. (2017). Organization change: Theory and practice (5 ${ }^{\text {th }}$ ed.). Thousand Oaks, CA: Sage Publications.

Burke, W. W. \& Litwin, G. H. (1992). A causal model of organizational performance and change. Journal of Management, 18(3), 523-545. https://doi.org/10.1177/014920639201800306

Chatman, J. A. (1989, July 1). Improving interactional organizational research: A model of person-organization fit. Academy of Management Review, 14(3), 333-349. Retrieved from http://amr.aom.org/

Coleman, P. T., Coon, D., Kim, R., Chung, C., Bass, R., Regan, B. \& Anderson, R. (2017). Promoting constructive multicultural attractors: Fostering unity and fairness from diversity and conflict. Journal of Applied Behavioral Science, 53(2), 180-211. https://doi.org/10.1177/0021886317702133

Davidson, M. N. (1999). The value of being included: An examination of diversity change initiatives in organizations. Performance Improvement Quarterly, 12, 164-180. https://doi.org/10.1111/j.1937-8327.1999.tb00121.x

Dobbin, F. \& Kalev, A. (2016, July-August). Why diversity programs fail. Harvard Business Review, 52-60. Retrieved from https://hbr.org/

Dowd, A. C. \& Bensimon, E. M. (2015). Engaging the" race question": Accountability and equity in US higher education. New York, NY: Teachers College Press.

Dowd, A. C., Bensimon, E. M., \& Witham, K. (2016, Winter). Five principles for enacting equity by design. Diversity and Democracy. Retrieved from https://www.aacu.org/diversitydemocracy/

Eagly, A. H. (2016). When passionate advocates meet research on diversity, does the honest broker stand a chance? Journal of Social Issues, 72(1), 199-222.

https://doi.org/10.1111/josi.12163 
Foldy, E. G. \& Buckley, T. R. (2017). Reimagining cultural competence: Bringing buried dynamics into the light. Journal of Applied Behavioral Sciences, 53(2), 264-289. https://doi.org/10.1177/0021886317707830

Golom, F. D. (2015). Creating systemic change around lesbian, gay, bisexual and transgender (LGBT) issues: A case analysis and recommendations. In J. C. Hawley (Ed.), Expanding the circle: Creating an inclusive environment in higher education for LGBTQ students and studies (pp. 107-126). Albany, NY: State University of New York (SUNY) Press.

Harvey, W. B. (2016, February 21). How many protests will it take to finally diversify our campuses. The Chronicle of Higher Education. Retrieved from http://www.chronicle.com

Kalev, A., Dobbin, F. \& Kelly, E. (2006). Best practices or best guesses? Assessing the efficacy of corporate affirmative action and diversity policies. American Sociological Review,_71(4), 589617. https://doi.org/10.1177/000312240607100404

Katzenbach, J. R., Steffen, I., \& Kronley, C. (2012, July-August). Culture change that sticks. Harvard Business Review. Retrieved from http://www.hbr.org.

Roberson, L., Kulik, C. T., \& Tan, R. Y. (2013). Effective diversity training. In Q. M. Roberson (Ed.), The Oxford handbook of diversity and work (pp. 107-126). Oxford, UK: Oxford University Press. https://doi.org/10.1093/oxfordhb/9780199736355.013.0019

Lewin, K. (1951). Field theory in social science. New York, NY: Harper.

Liang, D. W., Moreland, R. \& Argote, L. (1995). Group versus individual training and group performance: The mediating role of transactive memory. Personality and Social Psychology Bulletin, 21(4), 384-393. https://doi.org/10.1177/0146167295214009

Lilienfeld, S. O. (2017). Microaggressions: Strong claims, inadequate evidence. Perspectives on Psychological Science, 12(1), 138-169. https://doi.org/10.1177/1745691616659391

Locke, E. A. \& Latham, G. P. (2002). Building a practically useful theory of goal setting and task motivation: A 35-year odyssey. American Psychologist, 57(9), 705-717.

https://doi.org/10.1037/0003-066X.57.9.705

Lorsch, J. W. \& McTague, E. (2016, April). Culture is not the culprit. Harvard Business Review. Retrieved from http://www.hrb.org.

Meadows, D. (2008). Thinking in systems: A primer. Vermont: Chelsea Green.

Pasmore, W. A. (2011). Tipping the balance: Overcoming persistent problems in organizational change. In A. B. Shami, R. W. Woodman \& W. A. Pasmore (Ed.) Research in Organizational Change and Development, Vol. 19 (pp. 259-292). UK: Emerald Group Publishing Limited. 
Patton, L. D. \& Hannon, M. D. (2008). Collaborating with cultural centers and multicultural affairs offices. In S. Harper (Ed.), Creating inclusive environments for cross cultural learning and engagement (pp. 139-154). Washington, DC: NASPA.

Renn, K. (2009). LGBT and queer research in higher education: The state and status of the field. Educational Researcher, 39(2), 132-141. https://doi.org/10.3102/0013189X10362579

Ross, L. (1977). The intuitive psychologist and his shortcomings: Distortions in the attribution process. In L. Berkowitz (Ed.), Advances in Experimental Social Psychology (pp. 173-220). New York, NY: Academic Press. https://doi.org/10.1016/S0065-2601(08)60357-3

Schein, E. (2016). Organizational culture and leadership (5 ${ }^{\text {th }}$ ed.). Hoboken, NJ: Wiley.

Senge, P. M. (1990). The fifth discipline: The art and practice of the learning organization. New York: Doubleday.

Sue, D. W., Capodilupo, C. M., Torino, G. C., Bucceri, J. M., Holder, A. M., Nadal, K. L., \& Esquilin, M. (2007). Racial microaggressions in everyday life: Implications for clinical practice. American Psychologist, 62(4), 271-286. https://doi.org/10.1037/0003-066X.62.4.271

Syvantek, D. J. \& Brown, L. L. (2000). A complex systems approach to organizations. Current Directions in Psychological Science, 9(2), 69-74. https://doi.org/10.1111/1467-8721.00063

Thomas, D. A. (2004, September). Diversity as strategy. Harvard Business Review. Retrieved from http://www.hrb.org.

Wong, A. \& Green, A. (2016, April). Campus politics: A cheat sheet. The Atlantic. Retrieved from http://www.theatlantic.com 


\section{Author Information}

Dr. Frank D. Golom is an Assistant Professor of Applied Psychology at Loyola University Maryland, where he specializes in organizational psychology and the application of psychological principles to group and workplace settings. His expertise is at the intersection of workforce diversity, organization change and group dynamics. Dr. Golom has been an invited keynote speaker at several diversity and inclusion conferences sponsored by the American Association of Colleges and Universities (AAC\&U), and continues to publish in the area of workforce diversity and organization change. He has won several awards for his work, including two Best LGBT Research Awards from the Society for Industrial-Organizational Psychology and a highly commended paper award from Emerald Publishing. Prior to joining the faculty at Loyola, he served as Founding Associate Director of Executive Education Programs at Teachers College, Columbia University.

Frank D. Golom

Department of Psychology

Loyola University Maryland

4501 North Charles Street

Baltimore, MD 21210

Email: fgolom@loyola.edu

Telephone: 410-617-2241 